\title{
Prevalence, Awareness, and Control of Hypertension in Health Workers of Two Teaching Hospitals of Yaounde-Cameroon: The Hypertension Awareness Initiative (THAI) Pilot Survey
}

\author{
Sylvie Ndongo Amougou1,2*, Karen Kamgoum Tchokote ${ }^{3}$, Ba Hamadou ${ }^{1,4}$, Ahmadou Musa Jingi ${ }^{1}$, \\ Chris Nadège Nganou-Gnindjio1,4, Marie Ntep Ngwet ${ }^{3,4}$, Liliane Mfeukeu Kuaté ${ }^{1,4}$, \\ Bonaventure Jemea $^{2,5}$, Lucie Ebah Epok ${ }^{1}$, Dieudonné Danwé1, Samuel Kingue ${ }^{1,6}$ \\ ${ }^{1}$ Department of Internal Medicine and Specialties, Faculty of Medicine and Biomedical Sciences, University of Yaounde 1, \\ Cameroon \\ ${ }^{2}$ University Teaching Hospital, Yaounde, Cameroun \\ ${ }^{3}$ Institute of Medical Technologies, University of Douala, Cameroun \\ ${ }^{4}$ Central Hospital of Yaounde, Cameroun \\ ${ }^{5}$ Department of Surgery and Specialties, Faculty of Medicine and Biomedical Sciences, University of Yaounde 1, Cameroon \\ ${ }^{6}$ General Hospital of Yaounde, Cameroun \\ Email: *ndongoamougou@yahoo.fr
}

How to cite this paper: Amougou, S.N., Tchokote, K.K., Hamadou, B., Jingi, A.M., Nganou-Gnindjio, C.N., Ngwet, M.N., Kuaté, L.M., Jemea, B., Epok, L.E., Danwé, D. and Kingue, S. (2018) Prevalence, Awareness, and Control of Hypertension in Health Workers of Two Teaching Hospitals of YaoundeCameroon: The Hypertension Awareness Initiative (THAI) Pilot Survey. Open Access Library Journal, 5: e4820.

https://doi.org/10.4236/oalib.1104820

Received: August 1, 2018

Accepted: August 28, 2018

Published: August 31, 2018

Copyright (C) 2018 by authors and Open Access Library Inc.

This work is licensed under the Creative Commons Attribution International License (CC BY 4.0).

http://creativecommons.org/licenses/by/4.0/

\section{Abstract}

Introduction: High blood pressure is a public problem worldwide because of its high morbidity and mortality. The greatest burden is in low-income settings. The burden of disease has not been studied in health workers in our setting. Methods: Between December 2016 and June 2017, we carried out a cross-sectional descriptive and analytic study in two teaching hospitals in Yaounde, using the WHO STEP wise approach. Participants were consenting Physicians, Nurses, Midwives, and Nursing assistants of both sex, aged $\geq 21$ years. Results: A total of 266 health workers were screened-31 Physicians, 144 Nurses, 80 Nursing assistants, and 11 Midwives. Their mean age was 41.1 \pm 7.6 years (25 to 66 years), and $84.6 \%$ were females. The prevalence of Hypertension was $13.9 \%$, of which $54.1 \%$ were newly diagnosed-Awareness rate of $45.9 \%$. The control rate of known cases of hypertension was $64.7 \%$ (64.3\% in those on monotherapy, and $66.7 \%$ in those on bitherapy). Age $>40$ years, and adiposity were significantly associated with hypertension. Conclusion: Compared to the general population, the prevalence of hypertension amongst health workers was low, but with a high rate of un-awareness. 


\section{Subject Areas}

Internal Medicine

\section{Keywords}

Hypertension, Health Workers, Prevalence, Yaounde

\section{Introduction}

Hypertension is a public health problem worldwide due the high vascular morbidity and mortality [1]. It is responsible for about a third (17 millions) of all deaths per year worldwide. In 2008, approximately $40 \%$ of adults worldwide, aged $\geq 25$ years had hypertension, with the greatest burden of disease in sub-Saharan Africa (SSA) - prevalence of $46 \%$ in adults aged $\geq 25$ years. Between 1980 and 2008, the number of people with hypertension increased from 600 millions to 1 billion, and this is expected to reach 1.5 billion in 2025 [1]. In 2014, the prevalence of hypertension was $30 \%$ in the urban adult population of Cameroon, two third of which were newly diagnosed [2]. The prevalence of hypertension is increasing with time in our setting, even in the student milieu. Between 2009 and 2013 , the prevalence of hypertension increased from $5.9 \%$ to $20.8 \%$ in a group of 3357 University students [3]. Jingi et al. [4] reported a high rate of hypertension and associated high rate of unwareness in a group of Primary Care Physicians in rural and semi-urban settings, and they suggested the targeted screening and reporting of hypertension and other vascular risk factors.

The burden of hypertension amongst health workers in the urban setting is not known. The aim of this cross-sectional study was to describe the prevalence pattern of hypertension in health workers in two teaching hospitals in Yaounde-Cameroon. This work also aimed at creating awareness so as to avoid the scenario of sick health workers treating sick people.

\section{Methods}

Study design, settings, and participants: Between December 2016 and June 2017, we carried out a cross-sectional descriptive and analytic study in two teaching hospitals in Yaounde-Central Hospital of Yaounde (YCH) and the University Teaching Hospital of Yaounde (UTH) - using the WHO STEP wise approach [5]. Yaounde is the capital city of Cameroon, central African sub-region. The population is estimated at about 2 million inhabitants. Included in this study were consenting Physicians, Nurses, Midwives, and Nursing assistants, of both sexes, and aged $\geq 21$ years. We excluded pregnant women, and non-exploitable files (incomplete data or measurements).

Variables and Measurements. In WHO STEPs 1, we collected sociodemographic (age, sex, professional category, level of education, and marital status) and life style (alcohol consumption, tobacco use, physical exercise, fruit/vegetable 
consumption, salt/cube consumption) data in a face-to-face interview by a trained investigator. Data on personal or family history of vascular disease (stroke, myocardial infarction) were also collected. In WHO STEPs 2, their weight $(\mathrm{Kg})$ was measured in light clothing and no shoes with an electronic scale balance (precision of $100 \mathrm{~g}$ ), and their height $(\mathrm{m})$ with a stadiometer. We calculated the Body Mass Index (BMI) as the Weight $(\mathrm{Kg}) /$ Height squared $\left(\mathrm{m}^{2}\right)$. We measured their abdominal circumference in the up-right position midway between the iliac crest and the lower border of the rib in the mid-axillary line using a measuring tape. After resting for at least 10 minutes, we measured their blood pressure in both arms in the sitting position using an automatic BP monitor (OMRON ${ }^{\circledR}$ M2 Basic). Three measurements were recorded within intervals of 3 to 5 minutes. The average of all three recordings was considered. The arm with the highest average value was used to characterize the blood pressure status. Those with de novo high systolic BP $>140 \mathrm{mmHg}$, and or diastolic BP $>90$ $\mathrm{mmHg}$ were seen two days later for BP control. This was to ascertain the persistence of elevated BP.

Working definitions. These were adapted from the WHO STEP wise questionnaire [5]. We defined hypertension as a systolic BP $>140 \mathrm{mmHg}$, and or diastolic BP $>90 \mathrm{mmHg}$, or any participant on BP lowering medicine. We defined normal weight as a BMI of $18-24.9 \mathrm{Kg} / \mathrm{m}^{2}$, over weight as a BMI of $25-29.9$ $\mathrm{Kg} / \mathrm{m}^{2}$, and obesity as a $\mathrm{BMI} \geq 30 \mathrm{Kg} / \mathrm{m}^{2}$. We defined abdominal obesity as a waist circumference $>94 \mathrm{~cm}$ in males, and $>80 \mathrm{~cm}$ in females. High risk life style was defined as per WHO STEP wise standard questionnaire [5].

Sample size: This was estimated using the Cochrane formula. For an estimated prevalence of hypertension of $26.2 \%$ in a group of Primary Care Physicians in rural and semi-urban settings in Cameroon [4], and a 5\% accepted error, the estimated sample size was 297 participants. Considering a 10\% exclusion (refusal, not fulfilling inclusion criteria), at least 327 health workers were to be surveyed.

Data analysis. Data were analyzed using the software SPSS version 21 (IBM, Chicago IL, USA). We have presented continuos variables as means \pm standard deviation or medians when indicated. We have presented discrete variables as counts and percentages. We calculated the Odds ( $95 \%$ confidence interval) of having hypertension according to the presence or absence of predisposing factors and certain sociodemographic characteristics. A p value $<0.05$ was considered statistically significant for the observed associations.

Ethical statement. This work was approved by the institutional review board of the University of Douala. Administrative authorization was obtained from the competent Hospital authorities. This work was carried out in accordance with the declarations of Helsinki [6].

\section{Results}

The flow of the participants is shown in Figure 1. A total of 300 health workers were surveyed, of which 275 consented to participate-response rate of $91.7 \%$. 


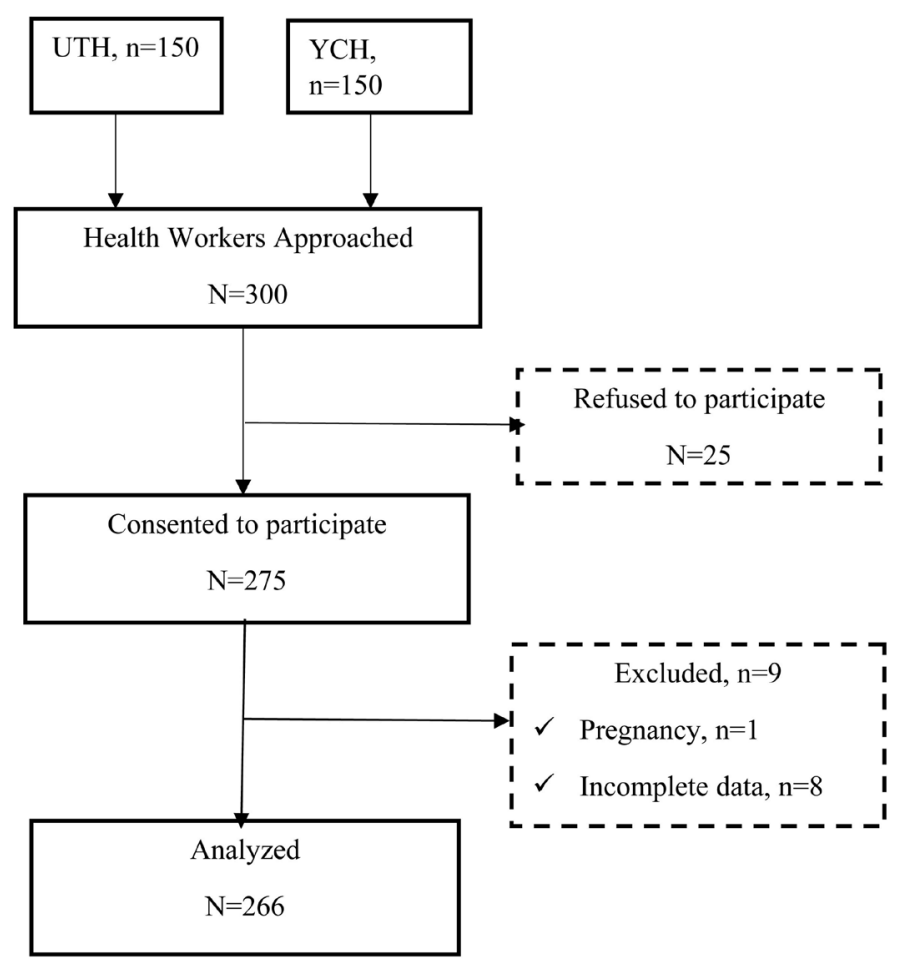

Figure 1. Flow of the participants.

We excluded 9 participants from the final analysis. A total of 266 health workers data were analyzed, of which 31 were Physicians, 144 were Nurses, 80 were Nursing assistants, and 11 were Midwives. Females made up $84.6 \%$ of the study population. Their mean age was $41.1 \pm 7.6$ years, and ranged from 25 to 66 years. The sociodemographic characteristics are shown in Table 1. Most of the participants were aged 40 to 49 years, and $67.5 \%$ were married. Nurses were the most represented of the health personnel. Hypertension was seen in 37 (13.9\%) participants, of which 20 (54.1\%) were newly diagnosed cases-Awareness rate of 45.9\%. Grade 1 hypertension was seen in $15(75 \%)$, grade 2 in $4(20 \%)$, and grade 3 in 1 (5\%) of the newly diagnosed cases. Of the 17 known cases, $64.7 \%$ had control of their blood pressure-64.3\% in those on monotherapy and $66.7 \%$ in those on bitherapy. The prevalence of hypertension according to the professional category is shown in Figure 2. Hypertension prevalence was highest in the Nurses. The predisposing factors of hypertension identified in those with the disease is shown in Table 2. Sedentarity (91.9\%), low consumption of vegetables (89.2\%), and abdominal obesity (73\%) were the most frequent predisposing factors of hypertension. The determinants of hypertension in the study population is shown in Table 3. Age $>40$ years, and high adiposity were significantly associated with hypertension.

\section{Discussion}

We carried out this cross-sectional pilot study using standard procedure with the aim of assessing the burden of hypertension in health care workers in two 
Table 1. Sociodemographic characteristics of the study population.

\begin{tabular}{|c|c|c|}
\hline Characteristics & Frequency (n) & Percentage (\%) \\
\hline \multicolumn{3}{|l|}{ Age range (Years) } \\
\hline $20-29$ & 20 & 7.5 \\
\hline $30-39$ & 85 & 31.95 \\
\hline $40-49$ & 112 & 42.1 \\
\hline $50-59$ & 47 & 17.7 \\
\hline$\geq 60$ & 2 & 0.75 \\
\hline \multicolumn{3}{|l|}{ Marital Status } \\
\hline Single & 63 & 26.6 \\
\hline Married & 160 & 67.5 \\
\hline Divorcee & 2 & 0.8 \\
\hline Widowed & 12 & 5.1 \\
\hline \multicolumn{3}{|l|}{ Level of Education } \\
\hline Secondary & 154 & 57.9 \\
\hline Higher & 112 & 42.1 \\
\hline \multicolumn{3}{|c|}{ Professional Category } \\
\hline Physician & 31 & 11.7 \\
\hline Nurse & 144 & 54.1 \\
\hline Nursing assistant & 80 & 30 \\
\hline Midwife & 11 & 4.2 \\
\hline
\end{tabular}

Table 2. Risk factors in those with Hypertension $(\mathrm{N}=37)$.

\begin{tabular}{ccc}
\hline Risk factors & Frequency $(\mathbf{n})$ & Percentage (\%) \\
\hline Distory of Pre-eclampsia/Eclampsia $(\mathbf{n}=\mathbf{3 2})$ & 4 & 12.5 \\
Damily History of Hypertension & 2 & 5.4 \\
Low consumption of Fruits & 22 & 59.5 \\
Low consumption of Vegetables & 20 & 54.1 \\
Consumption of Cube & 33 & 89.2 \\
Excessive consumption of Salt & 2 & 5.4 \\
Alcohol consumption & 20 & 54.1 \\
Tobacco consumption & 1 & 2.7 \\
Sedentarity & 2 & 5.4 \\
Obesity (Global) & 34 & 91.9 \\
Abdominal Obesity & 21 & 56.8 \\
& 27 & 73 \\
\hline
\end{tabular}


Table 3. Determinants of hypertension in the study population.

\begin{tabular}{|c|c|c|c|c|}
\hline \multirow{2}{*}{ Variable } & \multicolumn{2}{|c|}{ Hypertension } & \multirow{2}{*}{ OR $(95 \% \mathrm{CI})$} & \multirow{2}{*}{$p$ value } \\
\hline & Yes & No & & \\
\hline \multicolumn{5}{|l|}{ Sex } \\
\hline Male & $4(9.8)$ & $37(90.2)$ & $0.6(0.2-1.9)$ & 0.403 \\
\hline Female & $33(14.7)$ & $192(85.3)$ & & \\
\hline \multicolumn{5}{|l|}{ Age range (Years) } \\
\hline $20-30$ & $0(0)$ & $20(100)$ & l & 0.087 \\
\hline $30-40$ & $2(2.4)$ & $81(97.6)$ & $0.1(0.02-0.4)$ & $<0.001$ \\
\hline $40-50$ & $21(19.3)$ & $88(80.7)$ & $2.1(1.04-4.2)$ & 0.035 \\
\hline $50-60$ & $12(26.1)$ & $34(73.9)$ & $2.8(1.3-5.9)$ & 0.009 \\
\hline $60-70$ & $2(100)$ & $0(0)$ & I & 0.019 \\
\hline \multicolumn{5}{|l|}{ Level of Education } \\
\hline Secondary & $24(17.4)$ & $114(82.6)$ & $2.2(0.9-4.9)$ & 0.06 \\
\hline Higher & $9(8.9)$ & $92(91.1)$ & & \\
\hline \multicolumn{5}{|l|}{ Category } \\
\hline Physician & $4(12.9)$ & $27(87.1)$ & $0.9(0.3-2.8)$ & 0.999 \\
\hline Nurse & $21(14.7)$ & $123(85.4)$ & $1.2(0.6-2.3)$ & 0.726 \\
\hline Nurse assistant & $11(13.9)$ & $69(86.2)$ & $1(0.5-2.1)$ & 0.999 \\
\hline Midwife & $1(9.1)$ & $10(90.9)$ & $0.6(0.08-4.9)$ & 0.999 \\
\hline \multicolumn{5}{|l|}{ Predisposing factors } \\
\hline Pre-eclampsia/eclampsia & $4(22.2)$ & $17(77.8)$ & $1.7(0.5-5.6)$ & 0.318 \\
\hline Diabetes & $2(28.6)$ & $5(71.4)$ & $2.4(0.5-13.3)$ & 0.263 \\
\hline Family History & $22(16.3)$ & $113(83.7)$ & $1.6(0.7-3.4)$ & 0.248 \\
\hline Low fruit consumption & $20(14.4)$ & $119(85.6)$ & $1.1(0.5-2.2)$ & 0.813 \\
\hline Low Vegetable intake & $33(14.9)$ & $189(85.1)$ & $1.7(0.6-5.2)$ & 0.312 \\
\hline Consumption of Cube & $20(13.5)$ & $128(86.5)$ & $0.9(0.5-1.9)$ & 0.834 \\
\hline Excessive Salt Intake & $2(7.4)$ & $25(92.6)$ & $0.5(0.1-2.1)$ & 0.392 \\
\hline Alcohol consumption & $1(10)$ & $9(90)$ & $0.7(0.08-5.5)$ & 0.999 \\
\hline Tobacco use & $2(50)$ & $2(50)$ & $6.5(0.9-47.5)$ & 0.094 \\
\hline Sedentarity & $34(14)$ & $208(86)$ & $1.1(0.3-4.04)$ & 0.999 \\
\hline Obesity (Global) & $21(23.6)$ & $68(76.4)$ & $3.1(1.5-6.3)$ & 0.001 \\
\hline Abdominal Obesity & $27(20.6)$ & $104(79.4)$ & $3.2(1.5-7.01)$ & 0.002 \\
\hline
\end{tabular}

teaching hospitals in Yaounde-Cameroon. This was an effort to also create awareness in health care workers so as to prevent or control hypertension, thus preventing the scenario of sick health workers treating sick people. Hypertension was seen in about fourteen percent of the health workers, and this was associated with age $>40$ years, and high adiposity. 
PERCENTAGE (\%)

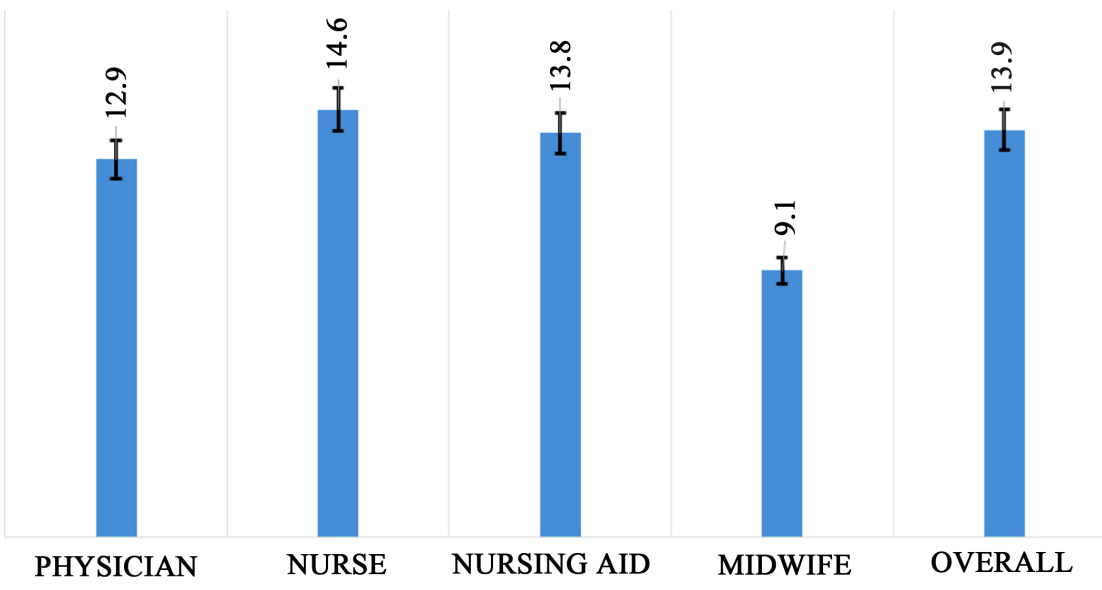

Figure 2. Prevalence of hypertension according to profession category.

Most of the health workers were between forty and fifty years of age. This was similarly reported by Konin et al. [7] in Ivory Coast. The female predominance was also reported by Valles et al. [8] in Spain. This was due to the higher proportion of Nurses. Females appear more likely to be Nurses than males. The prevalence of hypertension was comparable to the $17.5 \%$ reported by Konin et al. [7] in Ivory Coast, and significantly lower than the $26.2 \%$ reported by Jingi et al. [4] in a group of Primary Care Physicians in a rural and semi-urban settings in Cameroon. This was also significanlty lower than the $29.7 \%$ reported by Kingue et al. [2] in the Urban dwellers in Cameroon. Hypertension was significantly higher in health care workers who also have teaching activities [7]. Our findings were significantly higher than the $9.7 \%$ reported by Valles et al. [8] in Spain. These findings highlight the complex interaction of genetics and the environment in the occurrence of hypertension. In our sub-Saharan setting, rural health care workers were more likely to be hypertensives than urban health care workers. The rate of hypertension was significantly lower than that of the general population due to age registriction. Irrespective of age, high adiposity was constantly associated with the occurrence of hypertension. For a better understanding of the burden of hypertension, Jingi et al. [4] suggested that epidemiological studies on hypertension should be reported according to the professional category. Compared to other professional categories, the prevalence of hypertension in this study was significantly lower than the $49.3 \%$ and $20.9 \%$ reported by Ngombe et al. [9] in a group Millers and Security workers respectively in the Democratic Republic of Congo. Koffi et al. [10] reported a significantly higher rate of hypertension $(29.7 \%)$ in a group of seaport workers in Ivory Coast, and Fouda et al. [11] reported a significantly higher rate of hypertension $(24.8 \%)$ in a group of workers from six enterprises in Douala-Cameroon. These findings also highlight the complex interaction of the professional category and the occurrence of hypertension [12]. Thus, the health care profession appeared to be less associated with the occurrence of hypertension. This hypothesis has to be studied further. Workers with high socio-economic status in Jamaica have been shown 
to have higher rates of hypertension [13]. This could be associated with high level of stress involved with such professions. The low rate of awareness was comparable to that reported by Jingi et al. [4], and significantly lower than that reported by Konin et al. [7]. This stress the need for widespread and periodic screening of hypertension and related risk factors amongst health workers in our setting. Grade 1 hypertension was frequently seen in those with newly diagnosed hypertension. Timely and agressive strategies such as weight loss, increase in physical activities, and good eating habits could be beneficial at this stage of the disease. The control rate of those on treatment was acceptable, and this was comparable between those on monotherapy and those on bitherapy. However, this study was not sufficiently powered to assess the level of control of hypertension.

\section{Limitations}

This WHO STEPs 2 pilot study was limited to two teaching hospitals in Yaounde-Cameroon. Our findings could not be extrapolated to other hospitals in Urban and Rural settings. A WHO STEPs 3 study involving fasting blood glucose and lipid profile assessment could shed more light on the cardiovascular health of the health workers. This was limited by lack of finance. Despite this limitations, this pilot study sets the stage for further work and informed decision making.

\section{Conclusion}

Compared to the general population, the prevalence of hypertension amongst health workers was low, but with a high rate of un-awareness. This was associated with age $>40$ years and high adiposity. Sedentarity and poor eating habits-drivers of future development of hypertension-were also very frequent in this group of health workers. More epidemiologic studies of hypertension and awareness campagnes in the professional milieu are needed. Efforts should be made to reduce sedentarity and improve on the eating habits of health workers in our setting.

\section{Acknowledgements}

We thank the participants for accepting to participate in the survey.

\section{Disclosure}

None to declare.

\section{Funding}

None received for this study.

\section{Authors Contributions}

Conception and design: SNA, KKT, CNNG, SK. Data collection: SNA, KKT, 
CNNG, MNN, BH, LMK, BJ, LEE, DD. Data analysis and interpretation: SNA, KKT, CNNG, AMJ, DD, SK. Drafting of the manuscript: All the authors. All the authors approved of the final draft for publication.

\section{Conflicts of Interest}

The authors declare no conflicts of interest regarding the publication of this paper.

\section{References}

[1] World Health Organization (2013) A Global Brief on Hypertension. WHO/DCO/ WHD/2013.2.

http://apps.who.int/iris/bitstream/10665/79059/1/WHO_DCO_WHD_2013.2_eng. pdf

[2] Kingue, S., Ngoe, C.N., Menanga, A.P., Jingi, A.M., Noubiap, J.J.N., Fesuh, B., et al. (2015) Prevalence and Risk Factors of Hypertension in Urban Areas of Cameroon: A Nationwide Population-Based Cross-Sectional Study. Journal of Clinical Hypertension (Greenwich, Conn.), 17, 819-824. https://doi.org/10.1111/jch.12604

[3] Choukem, S.P., Kengne, A.-P., Nguefack, M.-L., Mboue-Djieka, Y., Nebongo, D. and Mbanya, J.-C. (2015) Tendances sur 5 ans de l'obésité et de la pression artérielle chez des jeunes adultes en milieu urbain camerounais. Diabetes \& Metabolism, 41, A97. https://doi.org/10.1016/S1262-3636(15)30365-7

[4] Jingi, A.M. and Noubiap, J.J.N. (2015) Cardiovascular Risk Factors Awareness and Prevalence among Primary Care Physicians: An Insight from the West Region Awareness Initiative Survey to Fight Cardiovascular Disease (WAIT-CVD) in Cameroon. BMC Research Notes, 8, 762. https://doi.org/10.1186/s13104-015-1747-y

[5] Riley, L., Guthold, R., Cowan, M., Savin, S., Bhatti, L., Armstrong, T., et al. (2016) The World Health Organization STEPwise Approach to Noncommunicable Disease Risk-Factor Surveillance: Methods, Challenges, and Opportunities. American Journal of Public Health, 106, 74-78. https://doi.org/10.2105/AJPH.2015.302962

[6] World Medical Association (1991) Declaration of Helsinki. Law, Medicine and Health Care: A Publication of American Society of Law and Medicine, 19, 264-265.

[7] Konin, C., Kramoh, E., Anzouan-Kacou, J.-B., N’Loo, A.E., Yayé, A., N’Djessan, J.J., et al. (2012) Approche diagnostique et prise en charge de l'hypertension artérielle chez le personnel soignant du district d'Abidjan (Côte d'Ivoire). Revue d Epidémiologie et de Santé Publique, 60, 41-46. https://doi.org/10.1016/j.respe.2011.07.006

[8] Valles, M., Mate, G., Bronsoms, J., Campins, M., Rosello, J., Torguet, P., et al. (1997) Prevalence of Arterial Hypertension and Other Cardiovascular Risk Factors among Hospital Workers. Medicina Clinica (Barc), 108, 604-607.

[9] Ngombe, L.K., Cowgill, K., Monga, B.B., Ilunga, B.K., Stanis, W.O. and Numbi, O.L. (2015) Prévalence de l'hypertension artérielle dans la population des meuniers de la ville de Lubumbashi, République Démocratique du Congo. Pan African Medical Journal, 22.

[10] Koffi, N.M., Sally, S.J., Kouame, P., Silue, K. and Nama, A.D. (2001) Facies de l'hypertension artérielle en milieu professionnela Abidjan. Médecine D'Afrique Noire, 48, 257-260.

[11] Fouda, A.B., Lemogoum, D., Dissongo, J.I.I., Manga, J.O., Tobbit, R., Moyo, D.N., et al. (2011) Etude épidemiologique de l'hypertension arterielle chez les travailleurs à 
Douala, Cameroun. Revue de Médecine et de Pharmacie, 1, 63-70.

[12] Hartung, D., Stadeler, M., Grieshaber, R., Keller, S. and Jahreis, G. (2010) Work and Diet-Related Risk Factors of Cardiovascular Diseases: Comparison of Two Occupational Groups. Journal of Occupational Medicine and Toxicology, 5, 4. https://doi.org/10.1186/1745-6673-5-4

[13] Miall, W.E., Kass, E.H., Ling, J. and Stuart, K.L. (1962) Factors Influencing Arterial Pressure in the General Population in Jamaica. British Medical Journal, 2, 497. https://doi.org/10.1136/bmj.2.5303.497 